\title{
Factors Associated With Quality of Life in Patients With Diabetic Foot Ulcers
}

\author{
Fariba Nasiriziba ${ }^{1}$; Davood Rasouli ${ }^{2,} ;$ Zahra Safaei $^{3}$; Dariush Rokhafrooz ${ }^{4}$; Alireza Rahmani $^{2}$ \\ ${ }^{1}$ Department of Nursing, ET, WOCN, Iran University of Medical Sciences, Tehran, IR Iran \\ ${ }_{3}^{2}$ Department of Nursing, Urmia University of Medical Sciences, Urmia, IR Iran \\ ${ }^{3}$ Department of Midwifery, Urmia University of Medical Sciences, Urmia, IR Iran \\ ${ }^{4}$ Department of Nursing, Ahvaz Jundishapur University of Medical Sciences, Ahvaz, IR Iran \\ *Corresponding author: Davood Rasouli, Department of Nursing, Urmia University of Medical Sciences, Urmia, IR Iran. Tel: +989141865057, E-mail: rasouli_d@umsu.ac.ir
}

Received: December 1, 2014; Accepted: January 1, 2015

Background: Diabetic foot ulcer (DFU) is a serious and costly complication in diabetes which affects approximately $15 \%$ of patients with diabetes and affects their quality of life (QOL).

Objectives: The purpose of this study was to investigate the factors associated with QOL in patients with DFU.

Patients and Methods: This cross-sectional study was performed on 60 patients ( 32 males and 28 females) hospitalized for DFU, performed through convenience sampling. Data related factors and the QOL questionnaire for patients with DFU were abridged. This questionnaire has 29 questions in six dimensions of enjoying life, physical health, daily activities dependence, negative emotions, concern about wound, and wound caring, which evaluate the QOL in patients with DFU. The scoring method for this tool is five optional Likert. Descriptive and analytic statistical methods were used to analyze the data.

Results: Of the 60 patients with DFU, 53\% were male and 47\% female with an average age of $58.08 \pm 11.95$ years and average QOL of $41.1 \pm$ 9.15. Statistical analysis showed that age $(\mathrm{P}=0.002)$, employment $(\mathrm{P} \leq 0001)$, socioeconomic status $(\mathrm{P}=0.016)$, leg ulcer $(\mathrm{P} \leq 0001)$, and the number of foot ulcer $(\mathrm{P}=0.017)$ had a statistically significant relationship with $\mathrm{QOL}$ and its dimensions. Other variables did not have a significant relationship with QOL, but some of them such as smoking during negative emotions $(\mathrm{P}=0.046)$ and marital status affecting the foot care difficulties $(\mathrm{P}=0.03)$ had significant statistical relationships with QOL.

Conclusions: Diabetic foot ulcer affects different aspects of life and can reduce patient's QOL. To improve the care behaviors and have a better control of foot ulcers and improve the QOL for these patients, taking into account factors such as age, occupation, marital status, number of wounds, and economic status is essential to plan for care and health needs in these patients.

Keywords:Diabetic Foot; Ulcers; Quality of Life

\section{Background}

Diabetes mellitus (DM) is one of the chronic metabolic diseases nowadays, the prevalence and incidence rate of which is increasing in Iran and throughout the world. Epidemiological estimations have revealed that the number of patients with DM will increase $122 \%$ by 2025 , so that it will reach from 135 million in 1995 to 300 million by 2025 (1). Diabetic foot ulcer (DFU) is among common and serious complications of DM which involve about $15 \%$ of patients with DM during their lives and causes $84 \%$ of lower limb amputations (2). According to some estimations, the prevalence rate of DFU will increase from 4\% in 1995 to $5.4 \%$ by 2025 (1). The mortality rate of these patients is 2.4 times greater than those without foot ulcers (3). Health sciences researchers have noticed the role of quality of life (QOL) in effective curing and caring of these patients in recent years (4). The QOL has one of the most important roles in effectiveness of the cares (5). DFU causes a reduction in QOL due to decreased mobility, increasing dependence to others and the risk of foot amputation, frequent referring to physicians and clinical care settings and increasing the expenditures (6). Some studies have suggested that DFU has significant effects on physical activities and psychosocial status of the patients (7). Nowadays, controlling chronic diseases has a special importance in medical care. In this condition, the goal of medical care is optimizing the patient's QOL. If QOL correction is the main goal of medical treatments, it must be considered as an outcome in theoretical researches (8). Karlsson et al. indicated the importance of paying attention to the QOL; today, instead of attention to indicators such as mortality and morbidity in patients, we must notice the broaden dimensions such as the QOL concept (9). Reduction of QOL not only causes decreased satisfaction but also may change the results of treatment and caring by affecting the patient's responsibility regarding caring and remedial orders $(10,11)$. Pinzur voiced that probably $85 \%$ of amputations are due to complications from diabetes-related foot ulcers and low QOL (12). Attention to treatment and protection from DFU has been promoted in recent decades (13). Paying attention to the effects of DFU on patients' QOL considering the today's knowledge is restricted (14).

\section{Objectives}

The study aimed to determine the effects of disease variables and demographic characteristics of patients with DFU on their QOL.

Copyright (C) 2015, Ahvaz Jundishapur University of Medical Sciences. This is an open-access article distributed under the terms of the Creative Commons Attribution-NonCommercial 4.0 International License (http://creativecommons.org/licenses/by-nc/4.0/) which permits copy and redistribute the material just in noncommercial usages, provided the original work is properly cited. 


\section{Materials and Methods}

This was a descriptive and analytical study performed on 60 hospitalized patients with DFU with the available sampling method. Data was collected using two questionnaires; the first one included some questions about the samples' demographic characteristics and the factors related to their illness and the second one was about some information regarding the QOL with short form diabetic foot ulcer scale (DFS-SF). This questionnaire has been designed by Johanson in England and its validity and reliability have been assessed in several countries. The reliability of this tool has been measured by Cronbach's alpha coefficient and its reliability has been proven with a score of 0.7. This questionnaire has 29 questions in six dimensions including enjoying life, physical health, daily activities dependence, negative emotions, concern about wound, and wound caring, which evaluates the QOL in patients with DFU. The scoring method of this tool is five optional Likert. After collecting the data, to extract the results, the specific rating scale of this questionnaire (the best score $=100$ and the worst score $=0$ ) were used. Content validity method was used for determination of validity in this research. After translating the questionnaire from English to Farsi, we provided it to 10 faculty members of the university editorial team; then, the corrected tool was used for data gathering. The Cronbach's alpha method was used for determination of reliability and score of $8 \%$ was obtained. Inferential descriptive statistical methods were used for data analysis. After investigation of data normality, independent t-test and nonparametric tests such as Mann-Whitney U-test and Kruskal-Wallis test were used.

\subsection{Ethical Considerations}

In this study, the researchers adhered to the following ethical considerations: respecting the subject's rights of their choices after consent and explaining the purpose of the study for all the subjects. The participants were assured that talking part in this study was voluntarily and they can quit at any time.

\section{Results}

Sixty patients with DFU participated in this study as samples. Table 1 shows the distribution of samples according to their age, gender, occupational status, location, economical status, body mass index (BMI), cigarette smoking, type of treatment, DFU background, location, and the number foot ulcers. The obtained mean and standard deviation of the total QOL of patients was $41.1 \pm 15.9$. Table 2 indicates the mean and standard deviation of the QOL in many dimensions. Generally, five from the total of 12 variables had significant statistical relationships with the QOL. Table 3 shows the relationship of the abovementioned variables with total QOL and its dimensions. Two variables of smoking in negative emotional status $(\mathrm{P}=0.046)$ and marital status from bothering dimension $(\mathrm{P}=0.03)$ had significant relationships with QOL, but there was not significant relationship among these variables and the total QOL.
Table 1. Demographic Characteristics of Patients With Diabetic Foot Ulcer Participated in the Study ${ }^{\mathrm{a}}$

\begin{tabular}{|c|c|}
\hline Variables & Values \\
\hline \multicolumn{2}{|l|}{ Gender } \\
\hline Male & $32(53.3)$ \\
\hline Female & $28(46.7)$ \\
\hline \multicolumn{2}{|l|}{ Residency } \\
\hline Tehran & $27(45)$ \\
\hline County & $33(55)$ \\
\hline \multicolumn{2}{|l|}{ Marital status } \\
\hline Married & $37(61.7)$ \\
\hline Single & $4(6.7)$ \\
\hline Widowed & $19(31.6)$ \\
\hline \multicolumn{2}{|l|}{ Employment status } \\
\hline Housewife & $16(26.7)$ \\
\hline Employed & $13(21.7)$ \\
\hline Unemployed & $20(33.3)$ \\
\hline Retired & $11(18.3)$ \\
\hline \multicolumn{2}{|l|}{ Income status } \\
\hline High & $6(10)$ \\
\hline Moderate & $34(56.7)$ \\
\hline Low & $20(33.3)$ \\
\hline \multicolumn{2}{|l|}{ Body mass index } \\
\hline Slim & $10(16.7)$ \\
\hline Normal & $24(40)$ \\
\hline Excess weigh & $15(25)$ \\
\hline Obese & $11(18.3)$ \\
\hline \multicolumn{2}{|l|}{ Cigarette smoking } \\
\hline Yes & $25(41.7)$ \\
\hline No & $35(58.3)$ \\
\hline \multicolumn{2}{|l|}{ Type of treatment } \\
\hline Insulin & $40(66.7)$ \\
\hline Oral medications & $20(33.3)$ \\
\hline \multicolumn{2}{|c|}{ History of foot ulcer } \\
\hline Yes & $21(35)$ \\
\hline No & $39(65)$ \\
\hline \multicolumn{2}{|c|}{ Location of foot ulcer } \\
\hline Under the big toe & $19(31.7)$ \\
\hline Metatarsus & $13(21.7)$ \\
\hline Both & $28(46.6)$ \\
\hline \multicolumn{2}{|c|}{ Number of foot ulcers } \\
\hline One & $24(40)$ \\
\hline Two & $17(28.3)$ \\
\hline Three & $13(21.7)$ \\
\hline Four & $6(10)$ \\
\hline
\end{tabular}

${ }^{\mathrm{a}}$ Date are presented as No. (\%).

Table 2. Mean Scale Scores for the Six Dimensions of the Quality of Life of Patients With Diabetic Foot Ulcer Participated in the Study ${ }^{\text {a }}$

\begin{tabular}{lc}
\hline Quality of Life Dimensions & Values \\
\hline Enjoying life & $39.08 \pm 17.23$ \\
Physical health & $44.08 \pm 18.21$ \\
Daily activities dependence & $42.33 \pm 23.18$ \\
\hline Negative emotions & $43.33 \pm 20.57$ \\
Concern about wound & $33.91 \pm 30.15$ \\
\hline Wound caring & $42.29 \pm 18.88$ \\
\hline a
\end{tabular}


Nasiriziba F et al.

Table 3. The Relationship Between Variables and the Quality of Life and the Dimensions in Patients With Diabetic Foot Ulcers Participated in the Study

\begin{tabular}{|c|c|c|c|c|c|c|c|}
\hline \multirow[t]{2}{*}{ Variables } & \multicolumn{7}{|c|}{ Quality Of Life Dimensions } \\
\hline & $\begin{array}{c}\text { Quality of } \\
\text { life }\end{array}$ & Enjoying life & $\begin{array}{l}\text { Physical } \\
\text { health }\end{array}$ & $\begin{array}{l}\text { Daily activities } \\
\text { dependence }\end{array}$ & $\begin{array}{l}\text { Negative } \\
\text { emotions }\end{array}$ & $\begin{array}{c}\text { Concern about } \\
\text { wound }\end{array}$ & $\begin{array}{l}\text { Wound } \\
\text { caring }\end{array}$ \\
\hline Age & 0.002 & 0.016 & 0.007 & - & 0.005 & - & 0.008 \\
\hline Gender & 0.490 & - & - & - & - & - & - \\
\hline Residency & 0.638 & - & - & - & - & - & - \\
\hline Marital status & 0.124 & - & - & - & - & - & 0.030 \\
\hline $\begin{array}{l}\text { Employment } \\
\text { status }\end{array}$ & 0.0001 & 0.001 & 0.003 & 0.022 & 0.017 & - & 0.007 \\
\hline Income status & 0.016 & - & - & - & - & - & - \\
\hline Body mass index & 0.370 & - & - & - & - & - & - \\
\hline Cigarette smoking & 0.130 & - & - & - & 0.046 & - & - \\
\hline Type of treatment & 0.204 & - & - & - & - & - & - \\
\hline $\begin{array}{l}\text { History of foot } \\
\text { ulcer }\end{array}$ & 0.081 & - & - & - & - & - & - \\
\hline $\begin{array}{l}\text { Location of foot } \\
\text { ulcer }\end{array}$ & 0.0001 & 0.009 & 0.002 & - & 0.0001 & - & 0.003 \\
\hline $\begin{array}{l}\text { Number of foot } \\
\text { ulcers }\end{array}$ & 0.017 & - & - & - & 0.019 & - & 0.017 \\
\hline
\end{tabular}

\section{Discussion}

The results of this study revealed that QOL and its dimensions in patients with DFU are in average range. Most studies have indicated that DFUs affect patients' social and familial lives as well as their daily activities and leisure times (15). Ashford assessed QOL of 21 patients with DFU and reported some procedures that their families were unable to follow, causing familial problems, which had negative effects on their QOL, such as wound dressing, moderate motility reduction, limited daily activities, eg, shopping and taking shower (16). Age is one of the most important factors affecting the QOL, which is among dimensions such as enjoying life, physical health, negative emotions, and wound care difficulties. Studies showed that these effects increase with age. Valensi described a significant relationship between age and various fields of DFS such as daily living activities, physical health, and dependence (17). Age has more effects on QOL in diabetic patients without DFU as well; in United Kingdom Diabetes Study (UKPDS), younger patients had more positive ideas about diabetes compared to older patients due to two reasons; first, the youthful optimism; second, youth's early disease stages (18). Occupational status affects the dimensions of enjoying life, physical health, independence in daily living, negative emotions, and wound care difficulties. The effect of job on QOL is due to financial problems; Kinmooned stated that most people are involved with economic problems because of lack of suitable jobs (19). Bord concluded that most of the patients who are afraid of their diseases may lose their jobs and may neglect the medical recommendations (15). Zgonis mentioned that
DFU had an important role on occupational status and recruitment problems and caused financial impression on patients' lives (20). Geringer found an independent relationship between socioeconomic and familial obstacles regarding caring and QOL. This relationship was as strong as the one between QOL and clinical variables, which patients consider as distress or as a factor affecting their QOL (21). Furthermore, the location of foot ulcer is one of the factors affecting the QOL which affects dimensions such as enjoying life, physical health, negative emotions and wound care difficulties, worsening the QOL. Ribu concluded that the QOL in patients with DFU has a significant relationship with the wound location, especially when it is in plantar and heel regions. He stated that this relation is due to patients' problems in subsets of energy (verve) and the physical function of the QOL tools (22). Valensi stated that patients whose ulcers were located in heel or dorsalis pedis region had better QOLs than the ones who developed wounds in their plantar regions or under their toes. The affected areas are leisure and friends (17). The number of ulcers affects dimensions such as negative emotions and wound care difficulties. Obviously, by increasing the number of ulcers, daily activities and treatment encounter a variety of problems. Valensi indicated a significant relationship between the QOL and the number of ulcers. He concluded that with increasing the number of ulcers, a reduction will develop in QOL which includes all its aspects (17). There was not a significant relationship between marital status and QOL, but with the wound care difficulties, there was a significant relationship. Perhaps, 
married patients get more annoyed than unmarried patients and sometimes think that they cannot support their families during the wound care period. This study showed that there was a significant statistical relationship between smoking and negative emotions dimension of the QOL, which might be due to the fact that these patients have understood the effects of tobacco on creation and development of ulcers; however, most of them were not able to quit and have a negative outlook on life. Jahanloo et al. concluded that the level of QOL in smokers was significantly lower than nonsmoker patients and the concentration ability in smokers was less than that of nonsmokers. They also showed that negative feelings such as anxiety and depression in smokers were more than others (23). Similar to other chronic diseases, DFU causes a reduction in QOL by affecting various aspects of the patient's life. In addition, the results of other studies have shown that according to improvements in caring behaviors and better controlling of foot ulcers leading to higher QOL in these patients, it is necessary to consider factors such as age, occupation, marital status, number and ulcers locations, and economic conditions in planning for care and health care needs regarding these patients. Since this study was conducted among a limited population of patients with DFU, it will reduce the generalizability of our findings to the entire population of the country to some extent. However, considering the variables associated with the QOL for these patients in terms of their culture can play an important role in promoting the QOL in patients with DFU.

\section{Acknowledgements}

Hereby, we thank the Research Council of Iran University of Medical Sciences as well as the professors, endocrinology and diabetes departments staff, technical official personnel, and the participated patients hospitalized in Tehran Taleghani Hospital, for their sincere cooperation.

\section{Funding/Support}

This research was approved and financially supported by Iran University of Medical Sciences.

\section{References}

1. King H, Aubert RE, Herman WH. Global burden of diabetes, 1995 2025: prevalence, numerical estimates, and projections. Diabetes Care. 1998;21(9):1414-31.

2. Reiber GE. The epidemiology of diabetic foot problems. Diabet Med. 1996;13 Suppl 1:S6-11.
3. Boyko EJ, Ahroni JH, Smith DG, Davignon D. Increased mortality associated with diabetic foot ulcer. Diabet Med.1996;13(11):967-72.

4. Darvishpour Kakhaki AAJ, Yaghmaiee F, Alavi Majd F, Montazeri H. Evaluation of quality of life with disease and demographic variables in patients with diabetes referring to Tehran hospitals. JEndocrinol Metab. 2006(1):50-6.

5. Rubin RR, Peyrot M. Quality of life and diabetes. Diab Metab Res Rev.1999;15(3):205-18.

6. Sousa KH. Description of a health-related quality of life conceptual model. Outcomes Manag Nurs Pract.1999;3(2):78-82.

7. Goodridge D, Trepman E, Embil JM. Health - Related Quality of Life in Diabetic Patients With Foot Ulcers: Literature Review. J Wound Ostomy Continence Nurs. 2005;32(6):368-77.

8. Deyo RA. The quality of life, research, and care. Ann Intern Med. 1991;114(8):695-7.

9. Karlsson I, Berglin E, Larsson PA. Sense of coherence: quality of life before and after coronary artery bypass surgery--a longitudinal study. JAdv Nurs. 2000;31(6):1383-92.

10. Z RM. Factors affecting follow-up or follow-up treatment in patients with pulmonary tuberculosis clinics in Zahedan.Tehran: Shahid Beheshti Univ Med Sci Health Serv; 1996.

11. Osman L, Silverman M. Measuring quality of life for young children with asthma and their families. Eur Respir J Suppl. 1996; 21:35s-41s.

12. Pinzur MS, Gottschalk F, Smith D, Shanfield S, de Andrade R, Osterman $\mathrm{H}$, et al. Functional outcome of below-knee amputation in peripheral vascular insufficiency. A multicenter review. Clin Orthop Relat Res. 1993(286):247-9.

13. Jeffcoate WJ, Harding KG. Diabetic foot ulcers. Lancet. 2003; 361(9368):1545-51.

14. Hux MMN, Torrance G, Gibbald G. Health related quality of life related to chronic foot ulcers in diabetics. Qual Life Res. 1998;8:655.

15. Bord M. Quality of life issues in patients with diabetes and lower extremity ulcers: patients and care givers. Qual Life Res. 2004;7:365-72.

16. Ashford RL, McGee P, Kinmond K. Perception of quality of life by patients with diabetic foot ulcers. Diabet Foot J. 2002;3:150-5.

17. Valensi P, Girod I, Baron F, Moreau-Defarges T, Guillon P. Quality of life and clinical correlates in patients with diabetic foot ulcers. Diabetes Metab. 2005;31(3 Pt 1):263-71.

18. Quality of life in type 2 diabetic patients is affected by complications but not by intensive policies to improve blood glucose or blood pressure control (UKPDS 37). U.K. Prospective Diabetes Study Group. Diabetes Care. 1999;22(7):1125-36.

19. Kinmond K, McGee P, Gough S, Ashford R. 'Loss of self': a psychosocial study of the quality of life of adults with diabetic foot ulceration. J Tissue Viability. 2003;13(1):6-8-12 passim.

20. Zgonis T, Stapleton JJ, Shibuya N, Roukis TS. Surgically induced Charcot neuroarthropathy following partial forefoot amputation in diabetes. J Wound Care. 2007;16(2):57-9.

21. Geringer ES, Perlmuter LC, Stern TA, Nathan DM. Depression and diabetic neuropathy: a complex relationship. J Geriatr Psychiatry Neurol. 1988;1(1):11-5.

22. Ribu L, Hanestad BR, Moum T, Birkeland K, Rustoen T. Healthrelated quality of life among patients with diabetes and foot ulcers: association with demographic and clinical characteristics. $J$ Diabetes Complications. 2007;21(4):227-36.

23. Jhanloo A, Kimiagar M, Vafaiee M, Heidarnia A, Sobhani SA. The relationship between knowledge, self-efficacy and quality of life in patients with diabetes to control blood sugar and fat consumption of tobacco. Hormozgan Med J;86(11):261-6. 